\title{
On Similarity between All-Known Elementary Particles and Resonances Mass Spectrum and Nuclei Atomic Weights
}

\author{
A. G. Syromyatnikov \\ St. Petersburg University, Physical Department - Universitetskaya nab., 7/9,199034, St. Petersburg, Russia 188300 \\ *Corresponding Author: alsyromyatnikov@mail.ru
}

Copyright (C) 2014 Horizon Research Publishing All rights reserved.

\begin{abstract}
It is showed generalization of discovering of the simple fact of proportionality between all elementary particles masses and 24 resonance masses in one side and nuclei masses in another side with some constant coefficient to all-known elementary particles and resonances masses. For resonances that linear dependence led to elementary particles type when electric charge of ions is defined by the same charge of muons. In this approach neutral Higgs`s boson with it mass $125 \mathrm{GeV}$ connected with nucleus from the island of stability, so as neutral $\mathrm{Z}$ boson - to $\mathrm{U}-238$. On this set of quarks distribution their dilaton currents conservation is confirmed.
\end{abstract}

Keywords Dilaton or Scale Symmetry, Particles Photoproduction in Hypernucleus and Supernucleus

\section{Introduction}

Elementary particles and resonance production in high energy processes is characterized by scaling, when there is dilaton currents conservation low. It leads to fundamental definition of lepton number as a quantum dilaton number (see for example [1]) such as lepton generations are distinguished on masses only. In another side in the analogy it may be possible dilaton quarks currents conservation too.

In this work it is showed in possibility processes of elementary particles and resonance electroproduction on a threshold of spin shock-waves forming [1] in accelerated beams of ions of some stable chemical elements. In that case it may be possible start from the simple fact of proportionality between all elementary particles masses and 24 resonance masses [2-4] in one side and nuclei masses in another side with some constant coefficient to all-known elementary particles and resonances mass (see list [4]).

In that unexpected repeating of the whole by a fragments spectrum in 3 cases for particles and in 11 cases for resonances fit took admissible doubling of this calculated dilatation coefficient by means an ion electric charge doubling (in possibility processes of their electroproduction on a threshold of spin shock-waves (see [5]) forming [1] in accelerated beams of ions of some stable chemical elements; their photoproduction in hypernucleus and supernucleus also with one or two particles see [6-7]). Consideration of all known resonances from particles list [4] according to underlying pages show that a number of this cases electric charge doubling more 55 percent. Fundamentally in this case that $\mathrm{W}^{+}$boson of electroweak interaction in recalculating on mass directly join to a border of chemical elements stability through $\mathrm{Bi}-209$.

If so it be on more number of resonances then there mass spectrum are defined by chemical elements mass spectrum, relation charge to mass of electron, speed of light in vacuum and calculated threshold value spin shock-wave. Chemical elements (CE) masses are defined by a dilaton quark - lepton $\mathrm{X}$ - structure jump features [1].

1. Statistics - It is stated that there is 0.999952 correlations coefficient between series of 50 elementary particles masses spectrum and corresponding nuclei atomic weights. It is direct non statatistics dependence. So more this linear dependence of type $\mathrm{m}_{\mathrm{EP}}=\mathrm{aM}_{\mathrm{N}} \mathrm{Z}^{-1}+\mathrm{b}$ with $\mathrm{W}^{+}$boson of electroweak interaction in recalculating on At -210 and $Z^{0}$ boson on U-238 are characterized by standard deviation $\mathrm{a}=$ $0.4114 \pm 0.00058, \mathrm{~b}=16.32 \pm 25.18 \mathrm{MeV}$. Theoretically $\mathrm{a}=$ 0.411 .

There is 0.99872 correlations coefficient between series of 121 resonances masses spectrum and corresponding nuclei atomic weights. Linear dependence of type $m_{R E S}=a_{N} Z^{-1}+$ $b_{\text {res }}$ is characterized by standard deviation $a=0.4044 \pm$ $0.0019, b_{\text {res }}=67.4 \pm 17.3 \mathrm{MeV}$.

In whole there is 0.999882 correlations coefficient between series of 50 elementary particles and 121 resonances masses spectrum and corresponding nuclei atomic weights. Linear dependence of type $m=\mathrm{aM}_{N} \mathrm{Z}^{-1}+\mathrm{b}$ is characterized by standard deviation $\mathrm{a}=0.411014 \pm$ $0.00050, \mathrm{~b}=22.9 \pm 12.0 \mathrm{MeV}$. Theoretically $\mathrm{a}=0.411$. That high correlations does not be any simple coincidence. 
2. Below on table 1 all discovered 46 elementary particles and in table 2 all 121 resonances group in some sets for every ion kind on that occur their electroproduction as in [1] or more detailed on channals of hypernucleus ${ }_{\Omega}^{A} C E$ or ${ }_{\Omega \Omega}^{A} C E$ and supernucleus ${ }_{\Lambda}^{A} C E$ or ${ }_{1}^{A} C E$ photoproduction (CE chemical element nuclei, $A$-the hypernucleus or supernucleus mass, $\Omega$ - hyperon, $\Lambda$ - elementary particle or resonance). In this approach neutral Higgs`s boson with it mass $125 \mathrm{GeV}$ connected with nucleus from the island of stability, so as neutral $\mathrm{Z}$ boson - to $\mathrm{U}-238$.

Table 1. All discovered 46 elementary particles group in some sets for every ion kind on that occur their electroproduction

\begin{tabular}{|c|c|c|c|}
\hline $\mathrm{CE}^{1}$ & $\mathrm{~A}^{2}$ & $\mathrm{~B}^{3}$ & Particles \\
\hline $\mathrm{p}^{+}$ & 3 & \pm 32 & $\mathrm{~K}^{+}[493,7] \mathrm{K}_{\mathrm{LS}}^{0}[497,6] \eta^{0}[547,8]$ \\
\hline $\mathrm{He}_{3}$ & 8 & \pm 68 & $\begin{array}{c}\Delta^{0}, \Delta^{+}[1232] \Lambda^{0}[1232] \Sigma^{+}[1189,4] \\
\Sigma^{0}[1192,5] \Sigma[1197,4] \Xi^{0}[1315] \\
\Xi^{-}[1321]\end{array}$ \\
\hline $\mathrm{He}_{3}$ & 3 & \pm 170 & $\mathrm{p}^{+} \mathrm{n}[938] \Delta^{++}[1232]$ \\
\hline $\mathrm{He}_{3}$ & 1 & - & $\varphi[1019]$ \\
\hline $\mathrm{He}_{4}$ & 1 & - & $\Omega^{-}[1672]$ \\
\hline $\mathrm{Li}_{7}$ & 1 & - & $\Omega_{\mathrm{c}}^{0}[2698]$ \\
\hline $\mathrm{B}_{11}^{2+}$ & 1 & - & $\mathrm{D}[1870]$ \\
\hline $\mathrm{N}_{14}{ }^{2+}$ & 6 & \pm 110 & $\begin{array}{l}\Lambda_{\mathrm{c}}^{+}[2284] \Lambda_{\mathrm{c}}^{0}[2274] \Xi_{\mathrm{c}}^{+}[2466] \\
\Xi_{\mathrm{c}}^{0}[2472] \Lambda_{\mathrm{c}}^{-}[2284] \Xi_{\mathrm{c}}^{-}[2466]\end{array}$ \\
\hline $\mathrm{C}_{12}{ }^{2+}$ & 2 & \pm 51 & $\mathrm{D}^{*}[2010] \mathrm{D}_{\mathrm{s}}^{*}[2112]$ \\
\hline $\mathrm{Be}_{9}$ & 1 & - & $\eta_{\mathrm{c}}[3592]$ \\
\hline $\mathrm{O}_{16}^{2-}$ & 2 & \pm 68 & $\mathrm{~J} / \psi[3097] \eta_{\mathrm{c}}[2980]$ \\
\hline $\mathrm{B}_{11}$ & 2 & \pm 42 & $\Psi^{\prime}[3685] \Psi^{\prime \prime}[3768]$ \\
\hline $\mathrm{C}_{12}$ & 1 & - & $\Psi^{\prime \prime \prime}[4415]$ \\
\hline $\mathrm{N}_{14}$ & 3 & \pm 45 & $\mathrm{~B}^{*}[5325] \mathrm{B}_{\mathrm{s}}^{0}[5366] \mathrm{B}_{\mathrm{s}}^{*}[5415]$ \\
\hline $\mathrm{O}_{15}$ & 7 & \pm 104 & $\begin{array}{c}\Lambda_{\mathrm{b}}^{0}[5624] \mathrm{B}_{\mathrm{s} 1}[5830] \mathrm{B}_{\mathrm{s} 2}[5840] \\
\Xi_{\mathrm{b}}[5629,6] \mathrm{B}_{1}[5721] \overline{\Lambda_{b}^{0}}[5624] \\
\bar{\Xi}_{b}[5629,6]\end{array}$ \\
\hline $\mathrm{O}_{16}$ & 2 & 0 & $\mathrm{~B}_{\mathrm{c}}^{+}[6277] \mathrm{B}_{\mathrm{c}}^{-}[6277]$ \\
\hline $\mathrm{Mg}_{24}$ & 1 & - & $\mathrm{Y}[9459,7]$ \\
\hline $\mathrm{Al}_{27}$ & 2 & \pm 166 & $Y^{\prime}[10018] Y^{\prime \prime}[10350]$ \\
\hline $\mathrm{Si}_{28}$ & 1 & - & $\mathrm{Y}^{\prime \prime \prime}[10573]$ \\
\hline \multicolumn{2}{|c|}{ average } & $\begin{array}{l} \pm 78 \\
\mathrm{MэB}\end{array}$ & \\
\hline
\end{tabular}

${ }^{1}$ Ions of chemical elements (electric charge +1 or -1 is omit)

${ }^{2}$ Number of particles in the set

${ }^{3}$ Standard deviation on distinguish between particles masses, $\mathrm{MeV}$

Table 2. All discovered 121 resonances group in some sets for every ion kind on that occur their electroproduction

\begin{tabular}{|c|c|c|c|}
\hline $\mathrm{CE}^{3}$ & $\mathrm{~A}^{1}$ & $\mathrm{~B}^{2}$ & Resonances \\
\hline $\begin{array}{c}\mathrm{D}_{2} \\
771 \\
\end{array}$ & 4 & $748 \pm 145$ & $\begin{array}{c}\rho^{+}[770] K^{*}[892] \omega[783] \\
\eta[548]\end{array}$ \\
\hline $\begin{array}{l}\mathrm{He}_{3} \\
1157\end{array}$ & 9 & $1102 \pm 115$ & $\begin{array}{c}\mathrm{f}_{0}[980] \mathrm{a}_{0}[980] \varphi[1019] \\
\eta_{1}[1170] \mathrm{a}_{1}[1230] \mathrm{b}_{1}[1230] \\
\mathrm{f}_{1}[1282] \mathrm{K}_{1}[1270] \mathrm{f}_{2}[1270] \\
\Delta_{0}[1230] \Sigma^{0}[1193] \Sigma^{+}[1190] \\
\Sigma^{-}[1197] \Xi^{0}[1314] \Xi^{0}[1322]\end{array}$ \\
\hline $\begin{array}{l}\mathrm{Li}_{7}{ }^{2+} \\
1338\end{array}$ & 5 & $1320 \pm 35$ & $\begin{array}{c}\eta[1294] \pi[1300] \mathrm{a}_{2}[1320] \\
\mathrm{f}_{0}[1370] \\
\mathrm{K}_{1}[14000] \pi[1400] \mathrm{K}_{0}^{*}[1430] \\
\mathrm{K}_{2}^{*}[1430] \mathrm{f}_{1}[1426]\end{array}$ \\
\hline $\begin{array}{c}\mathrm{He}_{4} \\
1542\end{array}$ & 6 & $1533 \pm 75$ & $\begin{array}{c}\rho[1450] \eta[1476] \mathrm{f}_{0}[1500] \\
\mathrm{f}_{2}[1525] \pi_{1}[1600] \pi_{2}[1645] \\
\Sigma[1385] \Sigma[1530] \Lambda[1405] \\
\omega[1650]\end{array}$ \\
\hline
\end{tabular}

\begin{tabular}{|c|c|c|c|}
\hline $\begin{array}{l}\mathrm{Be}_{9}^{2+} \\
1724\end{array}$ & $\begin{array}{l}2 \\
7\end{array}$ & $1840 \pm 40$ & $\begin{array}{c}\pi_{2}[1670] \omega_{3}[1670] \varphi[1680] \\
\mathrm{K}^{*}[1680] \rho_{3}[1700] \mathrm{f}_{0}[1710] \\
\mathrm{K}_{3}[1770] \pi[1800] \chi[1835] \\
\mathrm{K}_{2}[1820] \\
\varphi_{3}[1850] \pi_{2}[1880] \\
\Sigma[1650] \Sigma[1670] \\
\Xi[1690] \\
\Sigma[1750] \Lambda[1800] \Lambda[1810] \\
\mathrm{K}_{2}[1770] \\
\Lambda[1820] \Xi[1820] \Lambda[1890]\end{array}$ \\
\hline $\begin{array}{l}\mathrm{B}_{11}^{2+} \\
1931\end{array}$ & 8 & $1968 \pm 45$ & $\begin{array}{c}\Sigma[1915] \Sigma[1940] \\
\Xi[1950] \Sigma[2030] \\
\Xi[2030] \Lambda[2100] \\
\mathrm{f}_{2}[1950] \mathrm{f}_{2}[1959] \\
\Lambda[2110] \mathrm{a}_{4}[2040] \mathrm{D}^{*}[2007] \\
\mathrm{D}^{*}[2010] \mathrm{f}_{2}[2010] \mathrm{f}_{4}[2050] \\
\mathrm{K}_{4}^{*}[2045] \varphi[2170] \\
\end{array}$ \\
\hline $\begin{array}{l}\mathrm{C}_{12}{ }^{2+} \\
2145\end{array}$ & 6 & $\begin{array}{l}2283 \pm 55 \\
2280 \pm 80\end{array}$ & $\begin{array}{c}\Sigma[2250] \Omega^{-}[2250] \Lambda[2350] \\
\mathrm{f}_{2}[2300] \mathrm{f}_{2}[2340] \\
\mathrm{D}_{\mathrm{s} 0}^{*}[2317] \mathrm{D}_{2}^{*}[2160] \\
\mathrm{D}_{\mathrm{s} 1}[2460] \mathrm{D}_{1}[2420] \\
\end{array}$ \\
\hline $\begin{array}{c}\mathrm{Li}_{7} \\
2676\end{array}$ & 6 & $2582 \pm 43$ & $\begin{array}{c}\Sigma_{\mathrm{c}}[2520] \Lambda_{\mathrm{c}}[2595] \\
\Lambda_{\mathrm{c}}[2625] \Xi_{\mathrm{c}}[2645] \\
\mathrm{D}_{\mathrm{s} 1}[2536] \mathrm{D}_{\mathrm{s} 2}[2572] \\
\end{array}$ \\
\hline $\begin{array}{l}\mathrm{O}_{15}{ }^{2-} \\
2868\end{array}$ & 7 & $2916 \pm 70$ & $\begin{array}{c}\Xi[3080] \Xi_{\mathrm{c}}[2800] \\
\Lambda_{\mathrm{c}}[2880] \Lambda_{\mathrm{c}}[2940] \\
\Xi[2980] \\
\eta_{\mathrm{c}}(1 \mathrm{~S} 1)[2980] \mathrm{J} / \psi[3097]\end{array}$ \\
\hline $\begin{array}{c}\mathrm{Be}_{9} \\
3447\end{array}$ & 5 & $3502 \pm 60$ & $\begin{array}{c}\chi_{c 0}[3415] \chi_{c 1}(1 \mathrm{P})[3511] \\
\chi_{c 2}(1 \mathrm{P})[3556] \mathrm{h}_{\mathrm{c}}(1 \mathrm{P})[3525] \\
\eta_{\mathrm{c}}(2 \mathrm{~S})[3637]\end{array}$ \\
\hline $\begin{array}{l}\mathrm{F}_{19}{ }^{2-} \\
3639\end{array}$ & 1 & & $\psi(2 s)[3626]$ \\
\hline $\begin{array}{c}\mathrm{B}_{11} \\
3862 \\
\end{array}$ & 3 & $3894 \pm 140$ & $\psi[3770] \chi[3872] \psi[4040]$ \\
\hline $\begin{array}{c}\mathrm{Na}_{23}{ }^{2+} \\
4348\end{array}$ & 3 & $4280 \pm 130$ & $\begin{array}{c}\psi^{\prime \prime \prime}[4160] \chi[3872] \\
\psi[4415]\end{array}$ \\
\hline $\begin{array}{c}\mathrm{Mg}_{24.3} \\
9298 \\
\end{array}$ & 1 & & $\gamma[9460]$ \\
\hline $\begin{array}{l}\mathrm{Cr}_{52}{ }^{2+} \\
9925 \\
\end{array}$ & 3 & $9930 \pm 89$ & $\begin{array}{c}\chi_{b 0}(1 \mathrm{P})[9856] \chi_{\mathrm{b} 2}(1 \mathrm{P})[9912] \\
\gamma(2 \mathrm{~S})[10023]\end{array}$ \\
\hline $\begin{array}{c}\mathrm{Al}_{27} \\
10306\end{array}$ & 4 & $10251 \pm 80$ & $\begin{array}{c}\gamma(1 \mathrm{D})[10163] \\
\chi_{\mathrm{bo}}(2 \mathrm{P})[10232,5] \\
\chi_{\mathrm{b} 1}(2 \mathrm{~S})[10255,4] \gamma(3 \mathrm{~S})[10355]\end{array}$ \\
\hline $\begin{array}{c}\mathrm{Si}_{28} \\
10688 \\
\end{array}$ & 2 & $10720 \pm 140$ & $\gamma(4 \mathrm{~S})[10580] \gamma[10860]$ \\
\hline $\begin{array}{l}\mathrm{Ni}_{59}{ }^{2+} \\
11201 \\
\end{array}$ & 1 & & $\gamma[11020]$ \\
\hline \multicolumn{2}{|c|}{ average } & $\pm 70 \mathrm{MeV}$ & $\begin{array}{c}\text { Average distinguish between } \\
\text { electroproduction threshold } \\
\text { and set centre } \\
28 \pm 85 \mathrm{MeV} \\
\end{array}$ \\
\hline
\end{tabular}

${ }^{1}$ Number of particles in the set

${ }^{2}$ Standard deviation on distinguish between particles masses, $\mathrm{MeV}$

${ }^{3}$ Ions of chemical elements (electric charge +1 or -1 is omit)

Electroproduction threshold, $\mathrm{MeV}$

According to table 3 in average the every set consist of 18 quarks. The distribution on resonances also is characterized every set in average from 18 quarks in limits of the permissible dispersion.

Below in table 3 give collections of sets of table 1 in the 
distribution on a number of quarks with dublet nucleons addition. All it is in direct accordance with thesis (see [1]) dilaton supersymmetry about 18 degree of freedom for quark system as freedom fermions system in Veil - Cartan space time (see [8-10]).

\section{Discussion}

Displacement $b_{\text {res }}$ for resonances is more then for particles. In another side it may be possible leads to the same type as for particles when electric charge of ions is defined by the same charge of muons: $b_{\text {res }}=24.5 \mathrm{MeV}$. There is a lepton $\mathrm{e}^{-}-$ $\mu^{-}$universality.

According table 1, 2 elementary particles and resonances group to every electroproduction sets on a mass with a small dispersion 78 and $70 \mathrm{MeV}$ accordingly. In particularly it is SU(3) baryon octet, distinguishing from the well-known by two baryons from hyperons triplet $\Delta^{0,+,++}$ instead of two nucleons, $\mathrm{SU}(3)$ singlet $\Omega^{-}$et cetera. Two nucleons essentially distinguish on their mass from the other particles from octet included to the triplet with one from the hyperon triplet $\Delta^{0,+,++}$.

On the fact of proportion between all-known elementary particles masses and resonances masses [2-4] in one side and nuclei masses in another side of which is stated it may be possible that quark spectrum from particles and resonances forming on nuclei destruction also will be homogeneous distribution as a Fermi distribution.

Actually according to table 3, 4 quark distributions on electroproduction sets all-known elementary particles and resonances are homogeneous as Fermi distributions. Moreover the number of sets of particles 1, 2, 3, 5, 8 formed Fibonacci numbers series. As known Fibonacci numbers takes place in quality of the solution of a task about degeneration of a level in the dual model. It supposed the fact that there we have filling of any level from 18 degree of freedom on a number of quarks.

Standard deviation on a number of 18 quarks for particles and on totality particles and quarks whole is smaller than 2 . It means that the deviation from the homogeneity of the quark distribution turned out far from an observables border for the single quark.

Table 3. Quarks distribution on sets of 46 particles [4] electroproduction in ion beams

\begin{tabular}{|c|c|c|c|c|c|c|c|}
\hline $\begin{array}{l}\text { Number of particles } \\
\text { in set }\end{array}$ & 1 & 2 & 3 & 6 & 7 & 8 & \multirow{3}{*}{$\begin{array}{c}\text { Standard } \\
\text { deviation on } \\
\text { the number of } \\
\text { quarks }\end{array}$} \\
\hline Number of sets & 8 & 5 & 3 & 1 & 1 & 1 & \\
\hline $\begin{array}{c}\text { Total number of } \\
\text { quarks }\end{array}$ & 18 & 20 & 21 & 18 & 18 & 24 & \\
\hline $\begin{array}{c}\text { Deviation from the } \\
\text { average }\end{array}$ & -1 & 1 & 2 & -1 & -1 & $3.5 \sigma$ & $19.0 \pm 1.42$ \\
\hline
\end{tabular}

Table 4. Quarks distribution on sets of 121 resonances and 46 particles electroproduction in ion beams

\begin{tabular}{|c|c|c|c|c|c|c|c|c|c|}
\hline \multicolumn{2}{|c|}{1} & 2 & 3 & 4 & 5 & 6 & 7 & 8 & 9 \\
\hline \multirow{2}{*}{\multicolumn{2}{|c|}{$\mathrm{N}^{1}$}} & 1 & 2 & \multirow[t]{2}{*}{3} & \multirow[t]{2}{*}{3} & \multirow[t]{2}{*}{4} & \multirow[t]{2}{*}{4} & \multirow[t]{2}{*}{5} & \multirow[t]{2}{*}{6} \\
\hline & & & $1-2$ & & & & & & \\
\hline \multicolumn{2}{|c|}{$\mathrm{N}^{2}$} & & -2 & 2 & 3 & 1 & 3 & 2 & 1 \\
\hline \multicolumn{2}{|c|}{$\mathrm{T}^{3}$} & & 6,8 & 18 & 18 & 14 & 24 & 20 & 16 \\
\hline \multicolumn{2}{|c|}{$\mathrm{D}^{4}$} & & -4 & 0 & 0 & -4 & $\sim 2.5 \sigma$ & 2 & -2 \\
\hline & 10 & & 11 & 12 & 13 & 14 & 15 & 16 & 17 \\
\hline $\mathrm{N}^{1}$ & 6 & & 6 & 7 & 7 & 8 & 8 & 9 & 10 \\
\hline $\mathrm{N}^{2}$ & 2 & & 1 & 1 & 1 & 1 & 1 & 1 & 1 \\
\hline $\mathrm{T}^{3}$ & 24 & & 18 & 17 & 20 & 19 & 22 & 18 & 20 \\
\hline $\mathrm{D}^{4}$ & $2.5 \sigma$ & & 0 & -1 & 2 & 1 & 4 & 0 & 2 \\
\hline \multicolumn{8}{|c|}{ Standard deviation on the number of quarks } & \multicolumn{2}{|c|}{$18.00 \pm 2.35$} \\
\hline \multicolumn{8}{|c|}{$\begin{array}{l}\text { Standard deviation on the number of quarks for all particles from table } 4 \text {. (apart from the octet) and } \\
\text { resonances [4] No. 2-3, } 4-6,8,9,11-14,16-17\end{array}$} & \multicolumn{2}{|c|}{$\underline{18.06 \pm 1.98}$} \\
\hline
\end{tabular}

${ }^{1}$ Number of particles in set

${ }^{2}$ Number of sets

${ }^{3}$ Total number of quarks

${ }^{4}$ Deviation from the average 
By oneself fact of homogeneity of a quark distributions show a dilaton quark quantum number conservation (see [1]) as independent from kind of an electroproduction sets.

\section{Conclusion}

It's stated the fact of repeating of all-known elementary particles and resonances mass spectrum as whole of nuclei atomic weight of ions of some stable chemical elements with a coefficient in proportion to $\mathrm{M} / \mathrm{e}$ for an ion. It is signed that all-known elementary particles and resonances masses also as masses of stable chemical elements and isotopes are defined by positions of features - jumps of a quark - lepton dilaton $\mathrm{X}$ - structure [1].

It is stated that a quark distribution on electroproduction sets all-known elementary particles and resonances is homogeneous as a Fermi distributions. Moreover the number of sets of particles 1, 2, 3, 5, 8 formed Fibonacci numbers series. As known Fibonacci numbers takes place in quality of the solution of a task about degeneration of a level in the dual model.

It supposed the fact that there we have filling of any level from 18 degree of freedom on a number of quarks.

Dilaton supersymmetry thesis [1] about 18 degree of freedom for quark system as freedom fermions system in Veil - Cartan space - time is supposed exactly.

By oneself fact of homogeneity of a quark distributions show dilaton quark quantum number conservation (see [1]) as independent from kind of any electroproduction sets.

A border of chemical elements stability through $\mathrm{Bi}-209$ is defined by possible processes of electroproduction on a threshold of spin shock-waves forming in accelerated beams of ions radioactive Po and At on a mass of $\mathrm{W}^{+}$boson of electroweak interaction.

That all gives addition arguments for observing in Veil Cartan space - time $\mathrm{V}_{4}$ of the threshold effect on GUT gravitation masses $\sim 3 \mathrm{TeV}$ for example in $\mathrm{BAC} p \bar{p}$ collisions (see [11]). $3 \mathrm{TeV}-$ it is $10^{-12}$ from physical GUT masses $3 \cdot 10^{15} \mathrm{GeV} \cdot 10^{-12}$ gives experimental value of distinguish between gravitation and inertial masses. There we have the only possibility in experimental operating by "tales" of giant GUT masses, so that Standard Model with Conformal Gauge Theory of Gravitation [1, 8-10] is correct.

\section{REFERENCES}

[1] SYROMYATNIKOV A. G. Physical effects in Con-formal Gauge Theory of Gravitation. (LAP Lambert Academic Publishing GmbH \& Co. KG, Saarbrucken, Germany) 2012. (in Russian)

[2] COLLINS P. D. B. and SQUIRES E. J., Regge poles in particle physics (Springer-Verlag, Berlin Heidelberg New York) 1968.

[3] OKUN L. B. Leptons and quarks (Nauka, Moscow) 1990. (in Russian)

[4] NAKAMURA K. et al. [Particle Date Groups], J PG 37, 075021 (2010) and 2011.

[5] SYROMYATNIKOV A. G., Vestnik Sanct Peter- burgskogo universiteta. Ser. 4. Vip. 2 (2012) 108-112. (in Russian).

[6] YAKAHASHI H., AHN J. K., AKIKAWA H. et al.,Observation of a Double Hypernucleus, Phys. Rev. Lett. 2001. Vol. 87, no. 21. P.212502.

[7] DONCHEV A. G., KALACHEV S. A., KOLESNI-KOV N. N. et al., Rus. Nuclear physics. 2004. V. 67. No. 12. P. 2178-2189.

[8] SYROMYATNIKOV A. G., Teor. and mat. Fiz., 87, №1, (April 1991) 157- 160 (in Russian).

[9] SATAROV A. G. and SyROMYATNIKOV A. G., Teor. and mat. Fiz., 92, №1, (june 1992) 150 (in Rus-sian).

[10] SATAROV A. G. and SYROMYATNIKOV A. G., Plenum Publishing Corporation (1993). P. 799 - 801.

[11] AALTONEN A., ARTIKOV A., BUDAGOV J. et al. Measurement of correlated production in collisions at GeV, Phys. Rev. D 77, 072004 (2008). 